\title{
Model-Based Family Health Promotion To Improve The Quality Of Life Of Children Aged 2-4 Years
}

\author{
Heni Puji Wahyuningsih ${ }^{1 a^{*}}$, Siti Tyastuti ${ }^{1}$ \\ 1 Midwifery Department of Health, Poltekkes Kemenkes Yogyakarta, Indonesia \\ ${ }^{a}$ henipujiw@gmail.com \\ * coresponding author
}

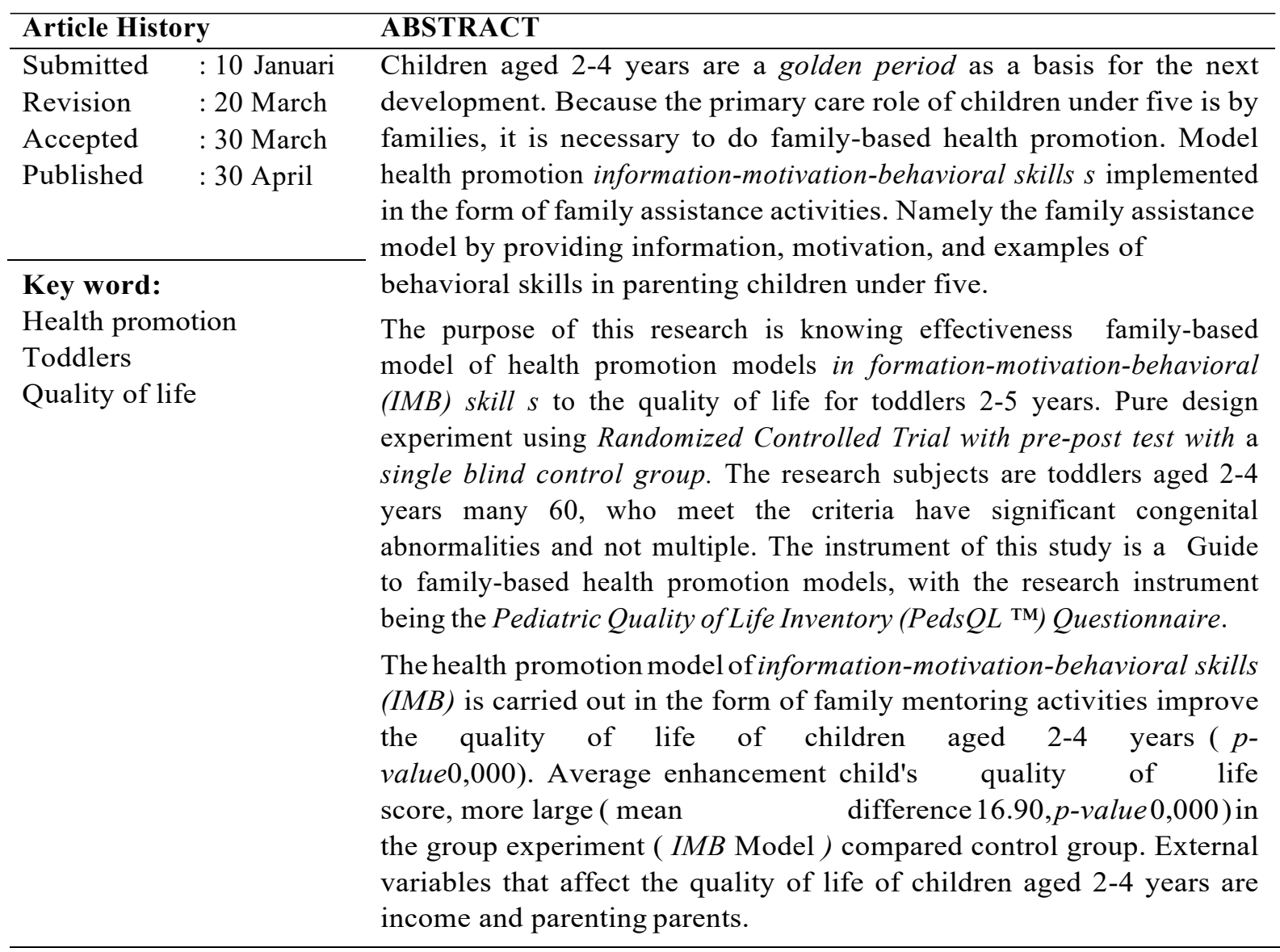

This is an openaccess article under the CC-BY-SAlicense.

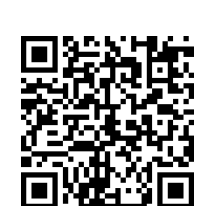

\section{Introduction}

A toddler is a golden period. In toddlers, this development of language skills, creativity, social awareness, emotional, and intelligence runs very fast and is the cornerstone of the next evolution.Moral development and the foundations of personality were also formed at this time. During this critical period, stimulation or stimulation was needed so that its potential develops. Child development will be optimal if the interaction was sought according to the needs of the child at various stages of development, even since the fetus is still in the womb. At 
this time it began to build an optimal quality of life to become the foundation element in the next period.

Quality of life is the individual's perception of the position of their lives in the context of the cultural system and the value of experience related to their goals, hopes, standards, and concerns. This is a broad and complex concept pertaining to physical health, psychological conditions, level of independence, social relations, personal beliefs and relationships with the environment ${ }^{1}$.

Quality of life related to health or Health-Related Quality of Life (HRQOL) is a multidimensional concept that is an individual's perception of the impact of a person's health status in terms of physical, psychological and social welfare. Quality of life is a broader concept than just measuring morbidity and mortality. Quality of life has been introducing in epidemiological sociology as a basis for planning, monitoring and evaluating interventions related to health 2. Variety of life assessments are increasingly recognized for decision making both in the clinical and community sphere 3 .

The quality of children's lives is one of the main problems in developing countries, including Indonesia. Children constitute the most significant proportion of the population in Indonesia at 33.9 percent or 82.6 million, with the most extensive distribution being 0-6 years of age, 32.6 million 4. Research on the quality of life of the children of the Healthy Families Health Status Assessment Program, which is a longitudinal study of 20,000 children in 20022003 using the Pediatric Quality of Life Inventory (PedsQL) instrument, which measures the quality of life of children by assessing physical, social, and emotions and school functions, showing children at risk of quality of life (children who must be considered for medical monitoring and intervention) in the Asian race by $13.2 \%$, Africa America $1.1 \%$ and America $0.3 \% 5$.

Based on the 2012 Household Health Survey (SKRT), data were obtained through interviews with parents, received by children aged 0-4 years with impaired daily activities including physical, communication and mental disorders amounting to $27.4 \%$. A study in Indonesia conducted in Bandung Regency, West Java showed that $20-30 \%$ of children under five had developmental disorders 6

Measuring quality of life is assessing individual perceptions of the impact of their health status. In adults, the ability to provide information about feelings and evaluation of the situation itself has been owned well. This is different from children who are still lacking in vocabulary, reading skills and cognitive functions that have not fully developed, so that children are less able to formulate judgments about purposes within themselves. This is what makes measuring the quality of life of children more difficult than adults. Most children submit various complaints through parents or caregivers. Parents are generally considered to be able to provide useful information about the functions and feelings of their children, so parents are the most appropriate proxy for providing information than teachers, doctors or nurses and midwives 7 .

Some measures of children's quality of life include Child Health Questionnaire, TAPQOL TNO-AZL Quality of Life Preschool Children, Quality Toddler Life Questionnaire TM (ITQOL), KIDSCREEN-52 and Peds QL. Peds QL is an instrument to measure the quality of life of children aged 2-18 years developed over 15 years 8 . Reliability was very good with Cronbach alpha values 0.88 for child questionnaires and 0.90 for parental questionnaires. PedsQL can distinguish the quality of life of healthy children with children who suffer from an acute or chronic illness and are using for various conditions of children's 
health. The questionnaire can be adopted internationally and has been translating into the Indonesian language 9.

Many factors influence the quality of life of children. These factors include: the age of the child, the more they age, the higher the risk of suffering from illness and stress; sex, women have a lower quality of life than men; education, the higher the child's education and parents the better the quality of life; other factors that affect quality of life are areas of residence; lack of access to health services;low socioeconomic / poverty; exposed home environment; presence of childhood disease (comorbidity); certain ethnic groups; house density / number of people in the household more than 5; number of siblings; problem of malnutrition / obesity; parenting parents who are too protective, parents who do not work . Low quality of life is also influenced by prenatal and perinatal factors, including congenital abnormalities; prematurity; low birth weightbabies).

The duties and responsibilities of parents in the family towards the education of their children are more of character education and character, skills training and social education. Both parents are the first and foremost educators for their children because before anyone else educates this child, both parents teach first. The role of learning parents is to educate at an early age.

Based on the results of a study of performance, the reduction in under-five mortality globally is still low. In Indonesia, the under-five mortality rate was 45/1000 live births in 2012 . The target of the MDGs in 2015 is 25 per 1000 live births, and it cannot be achieved, so hard work is needed to make these targets. One of the main objectives in the 2015-2019 RPJMN is the improvement of maternal and child health and nutrition status, then implemented through the Healthy Indonesia Program in the RI Ministry ofHealth Strategic Plan 2015-2019, applied with three main pillars, namely the good paradigm, strengthening health services and national health insurance. Part of the components of the strong paradigm pillar is carried out with a strategy to mainstream health in development, increasing the preventive promotion and community empowerment. In the first paradigm, it is stated that one of the centers of community empowerment is family. Part of the aspect of family health awareness indicators is the early stimulation of the development of toddlers.

Recommendations for post-MDGs 2015 health services in Indonesia to reduce infant and under-five mortality include that health is a fundamental right of every citizen, needs a commitment from all parties, community involvement, and participation or community empowerment to reduce maternal mortality and under-five mortality. Health promotion efforts are required to increase awareness, willingness and ability of families to improve maternal and child health, as well as make efforts to reduce maternal and child morbidity and mortality.

Monitoring the development and quality of life of children under five is not optimal, so family-based health promotion efforts for children under five become very important. Because the primary care role of children under five is by families, it is necessary to have family-based health promotion efforts. The Theory of Planned Behavior (TPB) promotion model is an extension of the Theory of Reasoned Action (TRA). In TRA, it is explained that one's intention towards behavior is formed by two main factors, namely attitude toward the behavior and subjective norms (Fishbein and Ajzen, 1975), while in TPB one more element is added, namely perceived behavioral control (Ajzen, 1991). The revision of TPB in 2002 added actual behavioral control (control of actual behavior. TPB is very suitable to be used to explain various health behaviors. Tori Planned Behavior 
(TPB) emphasize behavioral intention as a result of a combination of several beliefs. Purpose as" action plan to achieve behavioral goals ."Theory this is one from approach the most predictive persuasion. Through Home Visits Planned Behavior (TPB) is a theory about the relationship between beliefs and behavior. This theory states that the attitude toward the behavior, subjective norms, and perceived behavioral control, together forming only behavioral intention and actiuon 10 .

Social cognitive theory (Social Cognitive Theory) one of the concepts in the flow of behaviorism that emphasizes the cognitive component of mind, understanding, and evaluation. The social cognitive theory ( Social Cognitive Theory ) proposed by Albert Bandura states that social and cognitive factors, as well as actors, play an important role in learning. When children learn they can represent or transform their experiences cognitively. Social cognitive theory ( Social Cognitive Theory ) develops a reciprocal deterministic model which consists of three main factors, namely behavior, and environment. This factor can interact with each other in the learning process. Environmental factors influence behavior, behavior affects the environment, factor person / cognitive influences behavior. Social cognitive theory ( Social Cognitive Theory) describes human behavior in the context of continuous reciprocal interactions between cognitive, behavioral and environmental impacts. Environmental conditions around individuals are very influential in social learning patterns. According to Bandura, of all thoughts that affect human function, and is the most core part of the social cognitive theory is self-efficacy. Individuals who have high self-efficacy will be straightforward to face challenges. Individuals do not feel hesitant because he has a belief that is full of their abilities. These individuals will quickly face problems and be able to rise from failures experienced. The process of observing and imitating the behavior and attitudes of others as a model is an act of learning 11.

In this study, the model combines Behavior Theory Theory of Planned Behavior (TPB) with social cognitive theory (social cognitive theory) to improve the quality of life of children under five, which is a gold period. The implementation of the health promotion model used is in the form of the application of information-motivation-behavioral skills models implemented in the way of family assistance activities. This model was adopted from Bartholmae, 2016, namely the family assistance model by providing information, motivation, and examples of behavioral skills in parenting ${ }^{12}$.

\section{Material and method}

This type of research is quantitative research with pure experimental design using a randomized controlled trial with pre- post-test with a single-blind control group is a research design by giving treatment to the experimental group then the researcher tests the changes that occur after the experiment (surgery) and is compared with the control group, then for the outcome was blinded from the evaluator aspect.

The study began by determining the study population, namely all toddlers aged 2-4 years, who met the inclusion criteria: there were no congenital abnormalities or certain diseases, and it was not possible to be accompanied. The samples were divided into two groups, namely the treatment group (the application of the Family-Based IBM Health Promotion model ). The determination of the treatment group and control was done randomly. The second group sample then measured their quality of life before and after treatment and monitoring for three months of observation. 
The sample in the study were toddlers aged 2-4 years who did not experience significant congenital abnormalities and not multiple at birth until the time of data collection research, which resides in the working area of Mergangsan Health Center. The treatment group, namely toddlers, aged 2-4 years, applied the health promotion model in the form of implementation in motivation-behavioral skill s (IMB)models implemented in the way of family assistance activities. This model was adopted from Bartholmae, 2016, namely the family assistance model by providing information, motivation, and examples of behavioral skills in parenting children under five. The control group is toddlers aged 2-4 years who are treating with family without IBM models. The technique is using simple random sampling. Data analysis includes univariable analysis to present data descriptively such as frequency distribution and mean. Bivariable analysis using chi-square. Multivariable analysis using Cox regression.

\section{Result and discussion}

This research analyzes the influence of family-based health promotion models on the quality of life of children aged 2-4 years. The presentation of tables regarding the characteristics of the research subjects is as presented in Table 1.

Table 1. Social Characteristics of Demographics of Parents of Research Subjects

\begin{tabular}{|c|c|c|c|c|c|c|c|}
\hline Variable & $\mathrm{n}=60$ & $\%$ & $\begin{array}{c}\text { Treatment } \\
\text { Group } \\
\text { (IMB model) } \\
\mathrm{n}=30\end{array}$ & $\%$ & $\begin{array}{l}\text { Control } \\
\text { Group } \\
\mathrm{n}=30\end{array}$ & $\%$ & P value \\
\hline \multicolumn{8}{|l|}{ Father's } \\
\hline Education & 15 & 35 & 8 & 26.6 & 7 & 23.3 & 0.453 \\
\hline $\begin{array}{ll}\text { 1. } & \text { Basic } \\
\text { 2. } & \text { Continue }\end{array}$ & 45 & 75 & 22 & 73.6 & 23 & 76.6 & \\
\hline \multicolumn{8}{|l|}{ Mother's } \\
\hline Education & 19 & 31.6 & 10 & 33.3 & 9 & 30 & 0.543 \\
\hline $\begin{array}{ll}\text { 1. } & \text { Basic } \\
\text { 2. } & \text { Continue }\end{array}$ & 41 & 68.3 & 20 & 66.6 & 21 & 70 & \\
\hline \multicolumn{8}{|l|}{ Father's } \\
\hline occupation & 54 & 90 & 28 & 93.3 & 26 & 86.6 & 1,000 \\
\hline $\begin{array}{l}\text { 1. Work } \\
\text { 2. Does not } \\
\text { work }\end{array}$ & 6 & 10 & 2 & 6.6 & 4 & 13.3 & \\
\hline \multicolumn{8}{|l|}{ Mother's job } \\
\hline 1. Work & 34 & 56.6 & 18 & 60 & 16 & 53.3 & 0.730 \\
\hline $\begin{array}{l}\text { 2. Does not } \\
\text { work }\end{array}$ & 26 & 43.3 & 12 & 40 & 14 & 46.6 & \\
\hline \multicolumn{8}{|l|}{ Parent income } \\
\hline 1. High & 39 & 65 & 20 & 66.6 & 19 & 63.3 & 0,600 \\
\hline 2. Low & 21 & 35 & 10 & 33.3 & 11 & 36.6 & \\
\hline \multicolumn{8}{|l|}{ Marital status } \\
\hline 1. Marry & 55 & 91.6 & 28 & 93.3 & 27 & 90 & 0.900 \\
\hline $\begin{array}{l}\text { 2. Not } \\
\text { married }\end{array}$ & 5 & 8.3 & 2 & 6.6 & 3 & 10 & \\
\hline
\end{tabular}


Table 1. shows that parental social demographic factors namely father's education, mother's education, father's occupation, mother's work, parents' income, and marital status did not show differences between the treatment and control groups. This proves that the research subjects between the two groups based on social demographic factors have equal characteristics.

Table 4.2 Characteristics of Research Subjects

\begin{tabular}{|c|c|c|c|c|c|c|c|}
\hline Variable & $\begin{array}{l}n= \\
60\end{array}$ & $\%$ & $\begin{array}{c}\text { Treatment } \\
\text { Group } \\
\text { (IMB model) } \\
n=30\end{array}$ & $\%$ & $\begin{array}{c}\text { Control } \\
\text { Group } \\
\mathrm{n}=30\end{array}$ & $\%$ & $P$ value \\
\hline \multicolumn{8}{|l|}{ Child's age } \\
\hline 1. $\geq 3$ years & 38 & 63.3 & 18 & 60 & 20 & 66.6 & 0.626 \\
\hline 2. $<3$ years & 22 & 36.6 & 12 & 40 & 10 & 33.3 & \\
\hline \multicolumn{8}{|l|}{ Gender } \\
\hline 1. Women & 40 & 66.6 & 19 & 63.3 & 21 & 70 & 0.691 \\
\hline 2. Men & 20 & 33.3 & 11 & 36.6 & 9 & 30 & \\
\hline $\begin{array}{l}\text { Number } \\
\text { siblings }\end{array}$ & 11 & 18.3 & 5 & 16.6 & 6 & 20 & 0.773 \\
\hline $\begin{array}{l}\text { 1. Many }(>2) \\
\text { 2. Little }(\leq 2)\end{array}$ & 49 & 81.6 & 25 & 83.3 & 24 & 80 & \\
\hline $\begin{array}{l}\text { Row. Type of } \\
\text { childbirth }\end{array}$ & 20 & 33.3 & 9 & 30 & 11 & 36.6 & 0.578 \\
\hline $\begin{array}{l}\text { 1. Actions } \\
\text { 2. Spontaneous } \\
\text { Age of Gestation }\end{array}$ & 40 & 66.6 & 21 & 70 & 19 & 63.3 & \\
\hline 1. $\geq 32-37$ weeks & 41 & 68.3 & 22 & 73.3 & 19 & 63.3 & 0.766 \\
\hline 2. $<32$ weeks & 19 & 31.6 & 8 & 26.6 & 11 & 36.6 & \\
\hline Parenting & & & & & & & \\
\hline 1. Less & 21 & 35 & 11 & 36.3 & 10 & 33.3 & 0.626 \\
\hline 2. Well & 39 & 65 & 19 & 63.3 & 20 & 66.6 & \\
\hline
\end{tabular}

Table 2 Based on the subject characteristics of the child demographics (age, education, and gender) and the social, environmental factors of the child (parenting and number of siblings) and perinatal history (a type of labor and gestational age) showed no difference between the treatment and control groups ( P-value $>0.05)$. This indicates that based on demographic factors and social environment as well as the perinatal history between the two groups namely those who were treated with health promotion models of IBM and the control group had demographic characteristics and social environment as well as similar perinatal history. In this study, it was determined that the quality of life is useful if the average quality of life of children is $\geq 80$. Physical, emotional, social and school functions are considering good if the average physical purpose is $\geq 80$. Description of children's quality of life in the research subjects, both overall quality of life or based on each dimension (physical, emotional, social, school) presented in Table 3 below.

Table 3 Quality of life for children based on four dimensions

Dimension $\mathrm{n}=60 \quad \%$


Quality of Life:

1. Bad 13

2. Well

Physical function

1. Bad

2. Well

Emotion Function

1. Bad

2. Well

Social function

1. Bad

2. Well

School Function $(\mathrm{n}=32)$
15

45

25

75

14

23.3

46

76.6

12

48

20

80

$14 / 32$

43.75

$18 / 31$

2. Well

Table 4 shows that the quality of life of children is reduced in the study subjects by $21.6 \%$. Quality of life of children is terrible at the physical function by $25 \%$. Poor quality of life in emotional functions by $23.3 \%$, poor quality of life of children in emotional capacity by $23.3 \%$, poor quality of life on social tasks by $20 \%$. Quality of life-based on school functions was analyzed in children who had school totaling 32 children. The results show that children with lousy school functions are $43.75 \%$.

Table 5. Differences average S kor Quality of Life of Children 2-4 Years pretestposttest on Grou

\begin{tabular}{|c|c|c|c|c|c|}
\hline \multirow{2}{*}{$\begin{array}{l}\text { treatment } \\
\text { group }\end{array}$} & \multirow{2}{*}{$\mathbf{n}$} & \multicolumn{4}{|c|}{$\begin{array}{l}\text { Statistics } \\
\end{array}$} \\
\hline & & Mean & Enhancementpen & $\mathbf{T}$ & p-value \\
\hline Pretest & 30 & 66.3 & 1600 & 11,702 & 0,000 \\
\hline Posttest & 30 & 83.2 & 10.90 & & \\
\hline
\end{tabular}

Table 5 shows there are significant differences ( $p$-value 0,000$)$, the average quality of life score of children aged 2-4 years between pre-test (before treatment) and post-test (after surgery), there is an increase in children's quality of life score of 16.90 after treatment of the IBM health promotion model. This shows that the quality score of children has a significant increase in the study group that received treatment for the IBM health promotion model.

Table 6. Difference average S kor Quality of Life Children 2-4 years $P$ retest- postest on control

\begin{tabular}{lllcll}
\hline Treatment & \multirow{2}{*}{ Nroup } & \multicolumn{4}{c}{ Statistics } \\
\cline { 3 - 6 } & & Mean & Enhancement & T & p-value \\
\hline $\begin{array}{l}\text { Pretest } \\
\text { Posttest }\end{array}$ & 30 & 65.70 & 5467 & 7,474 & 0.120 \\
\hline
\end{tabular}

Table 6 shows no significant difference (p-value 0.120 ), the average quality of life score of children aged 2-4 years between pre-test (65.7) and the child's quality of life score in the post-test (70.23). This shows that in the control group that did not receive IMB treatment there was no significant increase in quality of life scores. 
Table 7. Differences Average Score Quality of Life for Children Aged 2-4 Years between Treatment withelompok control

\begin{tabular}{|c|c|c|c|c|c|c|c|c|}
\hline \multirow[b]{2}{*}{ Group } & \multicolumn{2}{|c|}{ Mean } & \multirow{2}{*}{$\begin{array}{l}\text { Mean of } \\
\text { difference }\end{array}$} & \multicolumn{2}{|c|}{$\mathrm{Cl}(95 \%)$} & \multirow{2}{*}{$T$} & \multirow{2}{*}{$d f$} & \multirow{2}{*}{$\begin{array}{l}p \text { - } \\
\text { value }\end{array}$} \\
\hline & Pretest & posttest & & Lower & Upper & & & \\
\hline Treatment & 66.30 & 83.2 & 16,90 & 13,946 & 19,854 & 11,702 & 29 & 0.00 \\
\hline Control & 65.70 & 70.23 & 5,467 & 3,971 & 6,963 & 7,474 & 29 & \\
\hline
\end{tabular}

Information : * Significant $(p$-value $<0.05)$

Table 7 There are significant differences ( $p$-value 0.00$)$ on the average score of quality of life for children 2-4 years between treatment groups compared to the control group. The average quality of life of children was higher (16.90) in the treatment group compared to the control group $(5,467)$. Then the treatment group has a more meaningful influence than the control group.

Table 8 Effect of Health Promotion Model IMB on Quality of Life of Children Under 4 Dimensions after control Factors dlain

\begin{tabular}{lcccccc}
\hline \multicolumn{1}{c}{ Variable } & B & SE & p-value & RR & \multicolumn{2}{c}{ CI (95\%) } \\
\cline { 2 - 7 } & & & & & Lower & Upper \\
\hline 1. Promotion health & 0.843 & 0.375 & 0.023 & 2,232 & 1,126 & 4,792 \\
$\quad$ Model & 0.154 & 0.459 & 0.747 & 1,604 & 0.643 & 4,002 \\
2. Parent education & 0.472 & 0.467 & 0.311 & 1,160 & 0,600 & 2,559 \\
3. Parents work & $-0,889$ & 0.388 & 0.022 & 0.411 & 0.192 & 0.880 \\
4. Income & $-11,602$ & 2043.4 & 0.995 & 0,000 & 0,000 & - \\
5. Parent's marital & & & & & & \\
$\quad$ status & 0.435 & 0.384 & 0.257 & 1,545 & 0.728 & 3,270 \\
6. Gender & 0.222 & 0.373 & 0.552 & 1,248 & 0.602 & 2,594 \\
7. Number of & $-0,072$ & 0.489 & 0.883 & 0.930 & 0.357 & 2,424 \\
$\quad$ siblings & & & & & & \\
8. Number of family & 0.842 & 0.370 & 2,323 & 1,126 & 0.643 & 4,793 \\
$\quad$ members at home & 0.215 & 0.467 & 0.311 & 1,604 & 0,600 & 2,559 \\
9. Birth weight & $-0,564$ & 0.470 & 0.231 & 0.569 & 0.226 & 1,431 \\
10. Gestational age & 0.276 & 0.666 & 0.010 & 1,318 & 0.357 & 4,867 \\
11. Type of labor & & & & & & \\
12. Parenting & & & & & & \\
\hline
\end{tabular}

Table 9 There is a significant influence ( $p$-value $<0.05$ ) IBM health promotion model variables as well as outside income variables and parenting patterns on the quality of life of children aged 2-4 years, after other factors have been controlling, for example health promotion models, education parents, parents 'work, parents' marital status, gender, number of siblings, number of members living in the same household, birth weight, age of friction, and type of delivery. The health promotion model variable determines 2.32 times in the four dimensions of a child's quality of life (95\% CI: 1,126-4,792). Parent income variables have a significant influence on the quality of life of children but are not risk factors or determinants of the four dimensions of a child's quality of life. Parenting variables are determinants of 1.318 times in 4 dimensions of children's quality of life (95\% CI: 0.357-4.867).

In this experimentp discusses the effect of health promotion model in the form of application information-motivation-behavioral skills $s$ (IMB) carried out in the way of family assistance activities in the treatment group, quality of life for toddlers 2-4 years in Puskesmas 
Mergangsan. While for the control group in this study were 2-4 toddlers who received regular care by parents, without a health promotionmodel.

\section{Quality of Life of Children aged 2-4 years}

The quality of life of children in this study was defined as the first parental / carer perceptions of children about children's health status in terms of physical, emotional, social and school well-being assessed using the Pediatric Quality of Life Inventory (PedsQL). Quality of life is measured using a proxy (determinant) the primary caregiver of the child. In this study most of them were mothers. According to Explanation Ethological theory of Bowlby (1969) cit, Van Der Horst (2008), the role of caregivers (mothers, grandmothers, aunts, etc.), consistency, and environment often with the child can read the sign - the sign or represent the child's response. Likewise, a consistent environment will make children closer to people and situations that are always with children. So that the child's primary caregiver is a determinant the most appropriate source of information in assessing the quality of life of children ${ }^{13}$.

Quality of life can be divided into the quality of life both good and bad. The quality of life in this study was also assessed based on each function, namely physical, emotional, social and school functions. In physical function, the aspect being evaluated is the child's ability to be independent in carrying out his activities. Assessment of physical function includes the child's ability to walk, run, play, lift heavy objects, take a bath, tidy up his toys, feel pain or pain and the child's energy level. This aspect of physical function is a child's behavior that can be observed by parents. The emotional purpose that is assessing is the child's ability to express anger, sadness, anxiety, fear and sleep problems. At the age of 2-4 years emotions easily change from one condition to another. The ability of children to display their emotional state is still lacking, so parents/caregivers will find it difficult to perceive children's emotions. This causes difficult emotional assessment of children with $a$ parent/caregiver proxy. Measurements of quality of life-based on parents' reports are more reliable in observable behavior but less reliable for emotional functioning 14

Social function, the aspect assessing is the child's ability to interact with peers. In social functions consist of 5 aspects including difficulties in getting along with children of the same age, other children do not want to be friends, mocked/ridiculed by other children, cannot do things that other children of their age can do, difficulties offset the game of their peers. Children's emotions strongly influence social functions. Children who experience emotional disturbances will cause their social functions to be disrupted.Emotions greatly affect a child's social interaction. Through emotions, children learn to change behavior, so they can adapt to social demands and measures. School functions in measuring the quality of life with Peds $Q L$ instruments are not assessments of children's cognitive aspects. Aspects assessed are related to the measurement of school activities related to children's physical function. School functions are only asking children who are already in school. The school in question is TK and PAUD, a school activity that children routinely undergo every day. Children who have gone to school in this study amounted to 32 children.

This study shows the proportion of children with the poor quality of life of $21.6 \%$, poor physical function $25 \%$, wrong emotional capacity $23.3 \%$, poor social function $20 \%$ and poor school function $43.75 \%$. This figure is higher than the results of a study conducted by the Managed Risk Medical Insurance Board ${ }^{5}$, which states that children from 
the Asian race have a risk of quality of life of $13.2 \%$. This is possible because the population of this study is children in urban areas, namely urban environments with high mobility. The work of parents, economic status, upbringing and quality of caregivers has a significant influence on the quality of life of children aged 2- 4 known ${ }^{1}, 5$.

\section{Effect of Family-based IBM Health Promotion Model on Quality of Life of Children}

The health promotion model is needed to facilitate understanding of the complexity and complexity of the theory and aims to make it easier to provide a simple picture to explain the method ${ }^{11}$. The model is the construction of a theoretical framework that describes the relationships between complex variables with simpler ones to make it easier to understand from a problem that represents many objects or overall activities. Thus, the health promotion model shows interactions between factors related to outcomes associated with the health promotion process. According to Tannahill (1985) are; 1) define the scope and objectives, 2) enable health promotion practitioners to understand what the motives of individuals and or communities adopt seeking or requesting health services, so that they can identify individual adverse behavior, 3 ) inform the development of health promotion programs to influence health behavior ${ }^{11}$.

According to Lewis et al. (2008) a health promotion model was developed for; 1) define the scope and objectives of learning, 2) enable health promotion practitioners to understand what individual motives and or communities adopt health-seeking or harm behavior, and 3) inform the development of health promotion programs to influence health behavior.

The development of the health promotion model continues to grow, WHO (1989) divides the health promotion model into several models; 1 ) health biomedical models (pre1970), 2) social health models (from 1970 onwards), 3) health ecology models (from the late 1970s onwards). Meanwhile, Lewis et al. (2008) divided the health promotion model into; Heel belief model, Social learning theory, Stages of change, Modern approach, Tannahill model, Beattie model, and Ewles \& Simnet model ${ }^{17}$.

Model health promotion information-motivation-behavioral skills $s$ (IMB) this was developed based on social theory and health psychology, including the Health Belief Model Theory, Transtheoretical Model, Attributable Risk, Reduction Model, TheoryofReasoned Action, Theory of Planned Behavior, and the Social Cognitive Theory. Model informationmotivation-behavioral skills $s$ (IMB) found in theories of social and health psychology, which is the interaction between the predictive validity of the critical ideas, conceptual parsimony, and constructs necessary for understanding and changes in health behavior. The IMB model has the advantage of being developed by combining various models of social theory and health psychology. The IMB model was designed to more easily translate health promotion models into intervention programs ${ }^{16}$, and this model has previously been used effectively before in behavioral changes related to children's health 2-4 know $\mathrm{n}^{17}$. Therefore the IMB model is the model developed in this study, as a more comfortable and more appropriate model for designing prevention efforts on the quality of life of children who are not good at age 2-4 years.

The Information-Motivation-Behavioral (IMB) model tends to explain many substances from variations in children's quality of life and physical activity better than some similar studies that have been reported by various literature for several reasons; the 
construct of the IMB is base on relevant health and social psychological theories. The IMB model is designed to be easier to translate into intervention programs. Furthermore, this theory is also validated empirically in various health areas. Using the right health promotion model is essential to help improve children's quality of life ${ }^{17}$.

According to Ewles and Simnet (1994) there are five approaches in formulating a health promotion model, namely; 1) medicine or prevention ( medical or preventive), 2) behavior change ( behavior change), 3) education (educational), 4) empowerment, and 5) social change ${ }^{11}$.

Based on the study of five approaches in formulating the health promotion model above, in this study adopted three main aspects which became modeling in health promotion, namely; behavior change ( behavior change), education (educational), and empowerment (empowerment). Behavior changes are sought through the provision of information or health education, as well as giving examples of behavioral skills about toddler care so that they can support changes in health behavior ( behavior change). The empowerment efforts referred to in the study areas family abilities which are part of the smallest unit of society to determine, analyze and act on their health problems through the role of family efforts that play a role in nurturing children aged 2-4 years. This is in line with the definition of health promotion in the Ottawa Charter, a process that allows individuals and communities to improve control over health determinants and thereby improve health. Community empowerment through the smallest participation is family 18.

In this study, the application of a health promotion model in the form of in motivation-behavioral skill $s$ (IMB) model was implemented in the way of family assistance activities. This model was adopted from Bartholmae, $2016{ }^{17}$, namely the family assistance model by providing information, motivation, and examples of behavioral skills about parenting children. The IMB model implementation is carried out for three consecutive months, namely June, July, August 2018 (mentoring is carried out every three weeks so that during the research period the IMB model is implemented four times). In this study prove a significant effect ( $p$-value 0,00) the application of the health promotion model in the formation of family-based behavioral skills (IMB) to the quality of life of children aged 2-4 years.

There is a significant difference ( $p$-value 0.00 ). The average quality of life of children 2-4 years between treatment groups are given the application of a health promotion model in the family-based formation of behavioral skills $s$ (IMB) compared to the control group. The average total quality of life of children occurred a higher increase (16.90) in the given treatment group compared to the control group $(5,467)$. So in the treatment group, the IBM health promotion model has a more significant influence on the quality of life of children aged 2-4 years compared to the control group. This is in line with the health promotion model according to French and Adama cit Naidoo and Wills (1996), that the application of the health promotion model as a hierarchical model through three phases includes; phase 1 models of behavior change, including behavioral and educational changes, stage 2 models of self and family empowerment, aimed at increasing family autonomy and ability to support health, and phase 3 is a model of collective action. Continued in the next explanation that the family-based health promotion model includes three steps, namely; 1) the stage of change in knowledge and attitudes, 2) the phase of 
improving life skills, understanding and decision making, 3) the step of increasing awareness, beliefs, and participation in action ${ }^{17,18,19}$.

The family is a miniature of the community, or it can be said that the family is a buffer for public health. The family is the smallest unit in society that must take efforts to improve public health. This is also in line with the concept of understanding families as a collection of individuals who live at home and have ties to blood or family relationships. The family has an essential role in making decisions and doing parenting, which affects the quality of life of children. The family is the first and foremost educator for children. Especially children aged 2-4 years is a critical period of toddlers, who experience a very potential development to realize the quality of life of children and generations of excellence. At the age of 2-4 years is the period of gold period towards children's growth and development. The importance of child care and the quality of life of children aged 2-4 years determine the formation of a qualified generation. So in line with the modeling developed in this study is a family-based model of health promotion, given the importance of the role of the family as a child educator, and has a fundamental role in the education and health of children aged 2-4 years ${ }^{20,21}$.

The implementation of the IMB model in this study is in line with the concept of empowering the community in health promotion or community-based health promotion (community-based health promotion). The community-based approach starts with a family-based approach. This can be referred to as a family-based health promotion model. It is called family-based health promotion when there is an activity of providing information or advice about health problems to the family ${ }^{17,20,21}$.

\section{External Variable Influence on Quality of Child Life}

There is a significant influence $(p$-value $<0.05$ ) family-based IMB health promotion model variables as well as outside income variables and parenting patterns on the quality of life of children aged 2-4 years, after other factors controlled, namely parents' education variables, parents' work, parents' marital status, gender, number of siblings, number of members living in a household, birth weight, gestational age, and type of delivery. The health promotion model variable determines 2.32 times in the 4 dimensions of a child's quality of life (95\% CI: 1,126-4,792). Parent income variables have a significant influence on the quality of life of children but are not risk factors or determinants of the four dimensions of a child's quality of life. Parenting variables are determinants of 1.318 times in 4 dimensions of children's quality of life (95\% CI: 0.357-4.867).

The economic status in this study was assessed based on per capita monthly expenditure both food and non-food according to the standards of Yogyakarta Province. High economic situation when the average expenditure $\geq$ Rp.1.500.000, - /capita/month, according to the standard minimum wage Yogyakarta province in 2018. In this study, the low economic status has a 0411 risk (95\% CI: 0192-0880) to have a poor quality of life compared to families with high economic status.

The female sex in this study was 1,545 times more risky to have a more inferior quality of life than men. This is consistent with the research of Gaspar et al. (2009) and Pradono et al. (2009) which states that men have a better quality of life than women. According to Najman et al. (2001), gender is one of the biases in measuring the quality of life using a proxy mother. This is because mothers more externalize boys and internalize girls, 20,21. 
Mother's work is a variable that plays a role in the relationship between health promotion models and children's quality of life. Mothers who do not work risk 1,160 times to have children with poor physical function. The results of this study are following the research of Simatupang et al. (2007) which states that the work of parents relates to the quality of life of children. The work refers to family economic status and family capacity to provide needs for children. In families with mothers who do not work, the family economy is only supported by the father, with the role of the mother in helping to make a living, it can improve the family economy which affects improving the quality of life for children. I bu who works is not guaranteed the development of children who are not good, because the most important thing is the quality of the relationship between child and mother and not the number of relationships, ${ }^{20,21}$.

Parental education in this study is not a confounding variable in the relationship between the health promotion model and the quality of life of children. Based on studies some high father education literature deals with broader opportunities to get jobs that can increase the income and family economy so that it can improve the quality of life for children 20,21.

Based on the results of this study, babies with birth weight $<2500$ grams have a risk of having a poor quality of life. According to Zwicker \& Harris (2008) and Chien et al. (2006) babies with meager birth weight have an impact on the quality of life of children up to adulthood. Based on this, birth weight is an important variable that needs to be considered to improve the quality of life of children.

Gestational age, in this study, showed that babies born $<32$ weeks, both at risk of having the poor quality of life, this is possible because. Children born with $<32$ weeks gestational age do not have organ maturity and thus have a significantly lower quality of life. The age factor of pregnancy is also an important variable that needs to be considered to improve the quality of life of children $21,23,24$.

In this study, most of the subjects $(65 \%)$ had good parenting. Children with good parenting risk 1.3 times to have a poor quality of life. The pattern of parenting will significantly affect the ability of children to interact socially (Month of 2009). Poor parenting such as lack of security in children can change other aspects of quality of life such as education and recreation because it can cause fear, anxiety, and anxiety so that the child is trying to get enough rest, do homework, participate and enjoy free time 20, $21,23,24$. With children having free time will give them the freedom to be involved in the activities they choose, this also provides an opportunity to expand children's social networks and can have a positive impact on aspects of quality of life 23,24 . However, children with parenting tend to be protective and even strict can cause poor quality of life.

So based on the above, it can be concluded that birth weight, gestational age, parental work, child care pattern, nutritional status, economy are also important things to consider to improve the quality of life of children. To prevent poor quality of life, the baby's weight must be considered since pregnancy by providing adequate nutritional intake.

\section{Conclusion}

Research on the effect of the family-based model of health promotion on the quality of life of children aged 2-4 years proves that; The method of health promotion informationmotivation-behavioral skills (IMB) carried out in the form of family assistance 
activities improves the quality of life of children aged 2-4 years ( $p$-value 0,000$)$. Average enhancement child's quality of life score, more large ( mean difference 16.90, $p$ value 0.000 ) in the group of the experiment ( Model IMB) compared to group Control. The outside variables that influence the quality of life of children aged 2-4 years are income and parenting parent ${ }^{23,24}$.

Based on the results of this study, it was recommended that health workers related to child health services in the community, to implement efforts to improve the quality of life of children aged 2-4 years using the health promotion model of the information-motivationbehavioral skills (IMB) applied in the form family assistance activities. Monitoring the health of the quality of life for children aged 2-4 years to be integrated with the monitoring of child growth and development. It is recommended to consider the parenting variables and characteristics of parents' income to improve the quality of life of children aged 2-4 years.

\section{Reference}

1. World Health Organization, 2006. WHO Child Growth Standards. WHO

2. Kernaghan, C., \& Kilroe, J. 2005. A Study on the Quality of Life of the KIDSCREEN tool for Children and Adolescent in Ireland. Minister for Children Dublin Department of Health and Children.

3. Petersen, S., Mavoa, H., Swinburn, B., Waqa, G., Goundar, R., Moodie, M.2012. Healthrelated quality of life is a secondary education school children in Fiji International Journal of Pediatrics.

4. Ministry of Women's Empowerment and Child Protection, and the Central Statistics Agency. 2012. Profile of Indonesian Children 2012. Jakarta.

5. Managed Risk Medical Insurance Board, M.2004. The Healthy Families Program Health Status Assessment (PedsQL). California.

6. Ministry of Health, 2012. Guidelines for Implementation of Early Detection Stimulation and Early Childhood Intervention in the Level of Basic Health Services. Jakarta. Ministry of Health.

7. Vogels, TC., Verrips, GHW, Koopman, HM, Theunissen, NCM. Fekkes, M., \& Kamphuis, RP2004.TACQOL, manually. The Leiden Center for Child Health and Pediatrics is a Permanent Joint Cooperation of TNO Prevention and Health and The Leiden University Medical Center.

8. Varni, JS1999. The PedsQL; Measurement Model for The Pediatric Quality of Life Inventory. Medical Care, 37 (2): 126-139.

9. Varni, JS, Seid, M., \& Kurtin, P.2001.PedsQL 4.0: Reliability and Validity of the Pediatric Quality of Life Inventory Version 4.0 Generic Core Scales in Healthy and Patient Populations. Medical Care, 39 (8), pp. 800-812.

10. Downie, RS, Tannahill, C and Tannahill, A. 1995, Health Promotion Models and Value. Second edition. Ms. York: Oxford University Press.

11. Ewles, L. \& Simnet, I. (1999). Promoting Health: A Practical Guide, Fourth Edition. London: Bailliere Tindall.

12. Egger, G., R. Spark, and R. Donovan. 2005. Health Promotion Strategies and Methods. Second Edition. Australia: Mc.Graw Hill Australia Pty Ltd.

13. Chien, LY, Chou, YL, Ko, YL, \& Lee, CF 2006. Health-Related Quality of Life Between 34 Years Old Children Born with Very Low Birthweight. Journal adv Nurse, 56 (1), pp. 9-16 
14. Eiser, C ..., \& Jenney, M.2007. Children's Quality of Life Measures. Arch Dis Child (77), pp. 350-354.

15. Kusmiyati, Y, 2016. Effects of Quality of Life of Children Aged 2-4 Years: Retrospective Cohort Study of Premature Babies, Dissertation of FKM Epidemiology Study Program, University of Indonesia. Jakarta.

16. Frost, R., Mel, \& Zuckerman, E., 2008, Health Promotion Theories and Models for Planning and Implementation Programs, University of Arizona, USA.

17. Collins, T. 2003. Models of Health: Pervasive, Persuasive and Politically charged. Second edition. Palgrave MacMillan. New York.

18. Fran Baum's book The New Public Health: An Australian Perspective (1998) is also an excellent book for further reading on these and other issues related to Health Promotion.

19. Glanz, K. Theory at a Glance: a Guide for Health Promotion Practice. See http://www.nci.nih.gov.

20. Agrina. 2009. Effect of parental characteristics and home environment on the development of children under five in the work area of Sidomulyo Health Center in Pekanbaru. Thesis. The University of Indonesia.

21. Aji, D, et al., 2009. Factors related to the quality of life of children with significant betathalassemia at the RSCM thalassemia center. Pediatric Sari.

22. Ariani, Novira, RY \& Yosoprawoto, M., 2012. Quality of life in children with heart disease. Brawijaya Medical Journal, 27(1).

23. Glanz, K. Theory at a Glance: a Guide for Health Promotion Practice. See http://www.nci.nih.gov.

24. Seid, M, Varni, JW, Segall, D., \& Kurtin, PS2004. Health-Related Quality of Life as a Predictor of Pediatric Healthcare Costs: a Two-Year Prospective Cohort Analysis. Health and Quality of Life Outcomes, 2, p.48. 